\title{
Current and Future Food Insufficiency During Covid-19: Examining Disparities by Race/Ethnicity and Recent Work Loss
}

\author{
Claire E. Altman ${ }^{1}$ (D) $\cdot$ Molly Dondero ${ }^{2} \cdot$ Colleen M. Heflin $^{3} \cdot$ Dashiell Nusbaum $^{2}$ \\ Received: 27 April 2021 / Revised: 13 July 2021 / Accepted: 18 July 2021 / Published online: 30 July 2021 \\ (C) W. Montague Cobb-NMA Health Institute 2021
}

\begin{abstract}
The Covid-19 pandemic, which began in early 2020, has eroded the previous decade's reductions in food insecurity. Pandemicrelated food insufficiency has been concentrated among Black and Hispanic households and those who have experienced a recent work loss. Households with children are particularly vulnerable. Using the first twenty-one weeks of the US Census Bureau's Household Pulse Survey data from April 2020 through December of 2020, we examine the association between recent work losses and food insufficiency and document the extent to which the impact varies by race/ethnicity. Work loss is predictive of current and future food insufficiency, with the association most acutely experienced by Blacks and Hispanics and households with children. There is evidence of racial/ethnic disparities in current and future food insufficiency. The results provide insight into how the pandemic has widened racial/ethnic gaps in the experience of food insufficiency despite recent policy interventions.
\end{abstract}

Keywords Food insecurity $\cdot$ Covid-19 $\cdot$ Race/ethnicity $\cdot$ Household Pulse Survey $\cdot$ Work loss

\section{Introduction}

In addition to serious and immediate health concerns, the Covid-19 pandemic, which began in early 2020, also created a household shock in the form of food insecurity. Food insecure households report being uncertain about having or acquiring food to meet the needs of their household members, representing a real, not perceived, financial strain with adverse consequences for health [1]. The precipitous rise in food insecurity stemming from the Covid-19 pandemic swiftly eroded the past decade's overall reductions in household food insecurity. In the decade following the Great Recession, from 2011 to 2019, rates of food insecurity among US households declined from a high of 14.9 to $10.5 \%$ [2]. Preliminary evidence from the first three months of the Covid-19 pandemic highlight staggering increases in food worries in American households [3-5]. Survey data collected in the early spring

Claire E. Altman

altmanc@health.missouri.edu

1 Department of Health Sciences and Truman School of Public Affairs, University of Missouri, Columbia, MO, USA

2 Department of Sociology, American University, Washington, DC, USA

3 Maxwell School of Citizenship \& Public Affairs, Syracuse University, Syracuse, NY, USA of 2020 suggest that an increasing number of households reported food insufficiency, or difficulties affording food and ensuring that household members have enough to eat $[1$, 6-8]. Additional evidence suggests that, like many impacts of the pandemic, the rise in food concerns early in the pandemic occurred unequally across racial groups, disproportionately burdening Black and Hispanic families [9], in part because those households have also been the most impacted by pandemic-related work losses. As the pandemic has continued for more than a year, food insecurity during the pandemic has transformed from an acute shock into a prolonged stressor, with potentially lasting, unequal compounding impacts that threaten to exacerbate existing racial disparities. This study examines racial disparities in food insufficiency in houses with work losses and with children over the course of the first 21 weeks during the pandemic.

\section{Household Work Loss During the Covid-19 Pandemic}

One key factor driving rising food insecurity is the unprecedented level of pandemic-related work losses. More than 40 million US adults filed unemployment claims between March and June of 2020 as more than 20 million jobs were lost during that same timeframe [10-12]. As stay-at-home orders were mandated in early spring 2020, many businesses shifted to remote work or shuttered, temporarily or permanently. As a result, the types of jobs lost during the pandemic were 
primarily concentrated in sectors that were incompatible with remote work including leisure and hospitality, travel and transportation, construction, service, self-employed, and manufacturing [13]. Moreover, the jobs lost were most frequently low or medium-wage or part-time positions [14-16]. The Chairman of the U.S. Federal Reserve, Jerome Powell, spoke to the immensity and concentration of unemployment reporting that nearly $40 \%$ of US households earning less than $\$ 40,000$ had experienced a work loss [17]. By the end of 2020 , the unemployment rate had improved, but only onehalf of the lost jobs had been recovered as upwards of 10 million Americans remained unemployed [18].

As with many aspects of the pandemic, the impact of work losses and food insecurity have not been uniform across demographic groups. Work losses have been borne most acutely by Black and Hispanics, households with children, and younger adults (ages 18 to 34), women, and those in lower paying jobs [16, 19-21]. These demographic groups tend to be concentrated in the types of jobs that were shuttered due to the pandemic. Consequently, groups such as Blacks and Hispanics have faced disproportionate work losses and have not experienced the same rates of work recovery as other racial/ethnic groups [22]. For example, while nearly $25 \%$ of all US adults had been laid off or lost wages due to the Covid19 pandemic as of August 2020, more than one-third of Hispanics reported a work loss compared to $29 \%$ of Blacks, $24 \%$ of Asians and 23\% of Whites [20]. Moreover, households with children have sustained significant work losses. Almost $20 \%$ of US children reside in a household that experienced a work loss in the early 2020 months of the pandemic and Black and Hispanic children are particularly vulnerable [23].

\section{Disparities in Food Insecurity}

Even prior to the Covid-19 pandemic, there were stark racial/ ethnic disparities in food insecurity, and households with children ${ }^{1}$ faced disproportionately high rates of food insecurity [7, 24]. In 2019, $19 \%$ of non-Hispanic Black households and $15.6 \%$ of Hispanic households were food insecure, respectively, compared to $8 \%$ of non-Hispanic White households [24]. Almost $14 \%$ of households with children under 18 were food insecure in 2019 compared to about $9 \%$ of households without children. These separate findings underscore the estimates that nearly $12 \%$ of non-Hispanic Black households have food insecure children compared to about $8 \%$ of Hispanic and $5 \%$ of non-Hispanic White households [24].

Therefore, the pandemic-related work losses further underscored the established, persistent association between unemployment and food insecurity for these households [19,

\footnotetext{
${ }^{1}$ It is important to note that there is significant overlap between these two demographic groups, that is, Black and Hispanic households with children.
}

21, 25]. Data from mid-spring 2020 suggest that the rate of food insecurity was nearly twice as high in households with recent work losses compared to households without losses [1, 19]. Households reporting a recent work loss were more likely to report sometimes not having enough food and having enough but not the types of food wanted compared to households without recent work losses [1, 8, 26]. Children have faced large increases in food insecurity during the pandemic [27]. The share of households with recent work losses reporting difficulty affording food for children was double that compared to households without work losses (31 vs. $14 \%$ ) [19].

Similarly, longstanding disparities in food insecurity between White households and Black and Hispanic households remain wide during the pandemic, due not only to differential work losses by race/ethnicity but also to persistent structural racism that has created concentrated disadvantages among people of color $[28,29]$. Such disadvantages include, for example, lack of access to grocery stores [30] and to reliable public transportation [31] as well as less savings and wealth $[32,33]$ and hinder reliable access to food and to safety nets that would buffer against food insecurity following a work loss. The cumulative effect of persistent and pervasive structural racism, in the form of racial discrimination in policies and in interpersonal interactions, can also influence future orientations and trust in institutions, making Black and Latino/a households more likely to perceive a higher risk of continued food insufficiency in the future.

We build on important and timely research investigating food insufficiency during the Covid-19 pandemic. To do so, we employ 21 weeks of the US Census Household Pulse Survey spanning April through December 2020 to provide a comprehensive portrait of the experiences of household food insufficiency in the first nine months of the pandemic. Whereas prior studies have documented food insecurity during the first week, first month(s), or selective weeks of the pandemic [5, 9], our study, by using data spanning nine months, offers a longer view that underscores the chronic nature of food insecurity during the pandemic. Furthermore, we examine racial/ethnic disparities in food insufficiency among those with recent work losses - and thus likely most susceptible - rather than among all adults as the impacts of the pandemic have not been evenly distributed based on employment status. Finally, we assess the racial/ethnic disparities in food insufficiency in households with work loss who have children. Some studies have examined the impact of an adult's work loss on child food security and the disproportionate impact of food insufficiency on Black and Hispanic children [23], but few, if any, examine the three jointly. Our research provides additional empirical evidence of the impact of Covid-19 work losses on existing racial/ethnic disparities in food insufficiency. 


\section{Data and Methods}

\section{Data and Analytic Sample}

We used data from the US Census Bureau's Public Use Files of the Household Pulse Survey, a web-based survey of adults 18 years of age and older measuring social and economic well-being during the Covid-19 pandemic [34]. Because these are anonymous, publicly available secondary data, this study was exempt by our Institutional Review Board. We use all the data collected in 2020 across 21 weeks: from April 23, 2020, to December 21, 2020. The Household Pulse captured a new sample on a weekly basis. Although there are other noteworthy smaller, regional, or non-probability surveys that have collected information on food sufficiency during the pandemic, the Household Pulse Survey is the only survey that is representative at the national and state level (and for $15 \mathrm{MSAs}$ ), when used with Census-provided survey weights. The Household Pulse was designed to quickly and efficiently collected data regarding household's experiences during the pandemic; the data are released in "near real-time" which is remarkable given the size of the sample and the scope of data collected [34].

Given the increase in work losses during the pandemic, we limit the sample to those who have experienced a recent work loss based on the question: "Have you, or has anyone in your household experienced a loss of employment income since March 13, 2020?" Those who answer 'yes' are included in the sample. Furthermore, we limit the sample to prime, working-aged adults 18-64. In further analyses, we limit to households with recent work loss and any children under the age of 18. Due to low levels of missing data, we use listwise deletion to account for item non-response. The final analytical sample for working-age households with work loss is 451,976 and for households with work loss and children under 18 the sample size is 206,515 .

\section{Measures}

\section{Dependent Variables}

Our primary focus is household food hardship faced the coronavirus pandemic, which we operationalize as food insufficiency. We use the term food insufficiency rather than food insecurity because the Household Pulse Survey asks about food insufficiency levels in the current and future weeks rather than food insecurity. The questions differ from the set of questions in the Current Population Survey's Food Security Supplement which, when used together, form a household food insecurity score.

In the Pulse, both questions were measured on a scale from 1 to 4 . The current week food insufficiency variable quantified households' levels of food sufficiency in the last 7 days, with
$1=$ "enough of the kinds of food (I/we) wanted to eat," $2=$ "enough, but not always the kinds of food (I/we) wanted to eat," 3 = "sometimes not enough to eat," and $4=$ "often not enough to eat". The future week food sufficiency question asked respondents how confident they were that their household would be able to afford the kinds of food they need in the next four weeks, with 1 = "Not at all confident," 2 = "Somewhat confident," 3 = "Moderately confident," and $4=$ "Very confident." The responses to the future week question were reverse coded so that a response of 1 would represent the lowest level of food insecurity and 4 would represent the highest.

We further dichotomized the food insufficiency measures, as done by other researchers also using the Household Pulse Survey [5]. For the current week, response categories 1 and 2 (enough to eat, enough to eat but not the kind of food wanted) constituted the reference 0 , while 3 and 4 (sometimes or often not enough to eat) were assigned 1 . We dichotomized future week food insufficiency by assigning only the 4th response (not at all confident) to $=1$, with all other responses $=0$. We treated this variable differently because "not at all confident" stood apart from the rest of the responses. The sample distribution of responses also allowed for this dichotomization.

\section{Independent Variable}

The primary independent variable of interest is race/ethnicity. Race/ethnicity is categorized as non-Hispanic White, nonHispanic Black, non-Hispanic Other, non-Hispanic Asian, and Hispanic; hereafter, White, Black, Other, Asian, and Hispanic.

\section{Control Variables}

We include the following independent variables: age measured categorically $(18-29 ; 30-39 ; 40-49 ; 50-59$; and $60-$ 64 ), sex (female $=1$ ), educational attainment categorized as less than high school, high school, some college, college, marital status categorized as married, never married, and widowed/divorced/separated, the number of children in a household under 18 years old, the number of adults 18 years or older in the household, whether the house is owned, rented, or lived in without payment, total household income (categorical from the US Census), and an indicator of self-rated poor health $(1=$ excellent; $5=$ poor $)$. We also include a control for the unemployment rate for the respective state and month in which a respondent was interviewed. Seasonally adjusted, monthly state unemployment data come from the St. Louis Federal Reserve Bank [35]. 


\section{Analytic Strategy}

We used descriptive statistics (means and proportions) to examine food insufficiency across racial/ethnic groups among households with recent work losses and among households with children. We further estimate multivariate logistic regressions predicting the dichotomous indicators of current and future food insufficiency separately. We conducted all analyses in Stata 14, using the survey-provided person weight and robust clustered standard errors at the state level. The survey weights were divided by the number of weeks of Pulse data pooled to generate national level estimates.

\section{Results}

Table 1 presents the weighted descriptive statistics for households reporting a recent work loss and households with a recent work loss and children. The respective groups are compared to households without a work loss and recent work loss without children using weighted bivariate regression models with robust standard errors clustered at the state level. About $44 \%$ of working-aged adults report a recent work loss; in households with children, nearly $47 \%$ of working-aged adults report a recent work loss. Among households with a recent work loss, almost $19 \%$ document current food insufficiency and $15 \%$ state future food insufficiency concerns. The proportion of households without a work loss who report current $(6 \%)$ and future $(4.5 \%)$ food insufficiency is markedly lower. Households with a recent work loss are disproportionately Black and Hispanic, younger, non-married, with lower levels of educational attainment, less likely to own their home, and have lower total household incomes and more people in the household. Notably, the means and frequencies for households with a recent work loss and households with a recent work loss and with children differ statistically significantly from their counterpart households without a recent work loss (with the exception of age 50-59 and female).

The descriptive values for households with recent work loss and children are shown in the third column of Table 1. Compared to other households that experienced work loss but do not have children (column 4), the recent work loss households with children report higher levels of current and future food insufficiency (21 and $16 \%$ vs. 16 and $14 \%$, respectively). Recent work loss households with children tend to be Black, Hispanic, aged 30-49, have either a high school or some college level education, live in large households, with an average of 4.8 persons nearly two of whom are children, and have low total household incomes. The means and frequencies are statistically different except for Asians, individuals who identified as "other" race, and home ownership status.

Table 2 presents the weighted descriptive statistics of current and future food insufficiency by race/ethnicity among households with a recent work loss. The racial disparities in current and future food insecurity are striking. There are clear racial/ethnic patterns as Asians had the lowest current and future food insufficiency rates (around 10\% for both), followed by Whites (15 and 12\%), individuals who identified as "other" (24 and 17\%), and Hispanics (24 and 20\%), with Blacks reporting the highest rates (28 and 21\%). Black and Hispanic households tend to have lower levels of educational attainment, have more children, live in a rented home, and have low total household incomes compared to Whites and Asians. Significant differences in means or frequencies between Whites and the other racial/ethnic groups (from bivariate weighted regressions) are indicated on the table.

In Table 3, we limit the sample to households with a recent work loss and children and present the descriptive statistics by race/ethnicity. The racial/ethnic patterns generally followed those described for Table 2. Yet, the high prevalence of current and future food insufficiency among households with work loss and children is noteworthy. More than $26 \%$ of other race and Hispanic households and 30\% of Black households report current food insufficiency, compared to $17 \%$ of White and $12 \%$ of Asian households. A larger portion of households with children report future food insufficiency worries than households without children with Blacks and Hispanics stating the most concern (nearly 1-in-5 households). Again, there were numerous significant differences between Whites and the other racial/ethnic groups as indicated on the table (tested using bivariate weighted regression).

Next, we turn to the logistic regression models predicting current and future food insufficiency, separately, among households with recent work loss shown in Table 4. Blacks, Hispanics, and individuals who identified as "other" have significantly higher log odds of reporting current and future food insufficiency compared to Whites. Asians have lower log odds of reporting current food insufficiency and are not significantly different from Whites on future food insufficiency. Relative to the youngest working-age adults, those 30-39 and 40-49 have significantly higher log odds of current and future food insufficiency while those 50-59 and 60-64 have significantly lower log odds (except for the 60-64 for future food). Adults with higher levels of education have significantly lower log odds of current and future food insufficiency compared to those without a high school degree. Larger households have higher log odds of current and future food insufficiency. Higher incomes are associated with lower log odds of current and future food insufficiency.

In Table 5, we estimate multivariate logistic regression models predicting both current and future food insufficiency among the households with a recent work loss, limiting the sample to households with children. While similar to the results for all working-age households with work loss, those with children differ in important ways. First, the racial/ ethnic patterns in current and future food insufficiency are 
Table 1 Weighted descriptive statistics among those with recent work loss and by child status

\begin{tabular}{|c|c|c|c|c|c|c|c|c|}
\hline & \multicolumn{2}{|c|}{ Recent work loss } & \multicolumn{2}{|c|}{ No recent work loss } & \multicolumn{2}{|c|}{ Recent work loss with children } & \multicolumn{2}{|c|}{ Recent work loss without children } \\
\hline & Mean & & Mean & Std. Dev & Mean & Std. Dev & Mean & Std. Dev \\
\hline Current food insufficiency & 18.63 & * & 6.38 & & 21.44 & $*$ & 16.15 & \\
\hline Future food insufficiency & 15.16 & * & 4.53 & & 16.46 & $*$ & 14.02 & \\
\hline Non-Hispanic White & 54.58 & $*$ & 64.35 & & 47.35 & $*$ & 60.99 & \\
\hline Non-Hispanic Black & 13.28 & $*$ & 11.09 & & 15.45 & $*$ & 11.35 & \\
\hline Non-Hispanic Asian & 5.35 & * & 6.05 & & 5.16 & & 5.51 & \\
\hline Non-Hispanic Other & 4.43 & * & 3.80 & & 4.56 & & 4.32 & \\
\hline Hispanic & 22.36 & $*$ & 14.71 & & 27.48 & $*$ & 17.82 & \\
\hline \multicolumn{9}{|l|}{ Age categories } \\
\hline $18-29$ & 24.01 & $*$ & 19.69 & & 19.17 & $*$ & 28.30 & \\
\hline $30-39$ & 23.64 & $*$ & 24.94 & & 31.38 & $*$ & 16.79 & \\
\hline $40-49$ & 21.77 & $*$ & 21.16 & & 29.99 & $*$ & 14.48 & \\
\hline $50-59$ & 21.53 & & 21.74 & & 15.62 & $*$ & 26.78 & \\
\hline $60-64$ & 9.05 & * & 12.46 & & 3.86 & $*$ & 13.65 & \\
\hline Female & 50.88 & & 50.73 & & 54.09 & $*$ & 48.03 & \\
\hline Less than high school & 9.74 & $*$ & 6.21 & & 12.93 & $*$ & 6.91 & \\
\hline High school & 31.04 & * & 26.11 & & 32.89 & $*$ & 29.39 & \\
\hline Some college & 33.96 & $*$ & 28.65 & & 32.47 & $*$ & 35.28 & \\
\hline College & 25.27 & * & 39.03 & & 21.71 & $*$ & 28.42 & \\
\hline Married & 50.78 & * & 57.38 & & 59.10 & $*$ & 43.40 & \\
\hline Never married & 33.68 & $*$ & 28.58 & & 25.98 & $*$ & 40.51 & \\
\hline Widowed/separated/divorced & 15.54 & * & 14.04 & & 14.92 & $*$ & 16.09 & \\
\hline Household size & 3.82 & $1.82 *$ & 3.31 & 1.68 & 4.81 & $*$ & 2.95 & 1.46 \\
\hline Household kids & 0.91 & $1.21 *$ & 0.81 & 1.14 & 1.93 & $1.06^{*}$ & & \\
\hline Household adults & 2.91 & $1.39 *$ & 2.49 & 1.23 & 2.87 & $1.29 *$ & 2.95 & 1.46 \\
\hline Own home & 58.78 & $*$ & 68.94 & & & 58.60 & 58.94 & \\
\hline Rent home & 39.22 & $*$ & 29.62 & & & 39.51 & 38.96 & \\
\hline Owe no house payment & 2.00 & $*$ & 1.44 & & & 1.89 & 2.10 & \\
\hline Total household income category & 3.76 & $2.05^{*}$ & 4.57 & 2.16 & 3.69 & $2.06^{*}$ & 3.83 & 2.05 \\
\hline Self-rated poor health & 2.66 & $1.07 *$ & 2.36 & 1.04 & 2.65 & 1.06 & 2.66 & 1.08 \\
\hline Month State Unemployment Rate & 9.71 & $3.77 *$ & 9.24 & 3.62 & 9.78 & $3.79 *$ & 9.64 & 3.75 \\
\hline & $\mathrm{N} 451,976$ & & N 568,768 & & N 206,515 & & N 245,461 & \\
\hline
\end{tabular}

Source: US Census Bureau Household Pulse Survey, Weeks 1-21, April 2020-December 2020

*indicates significant, $p<$ O.OS from weighted bivariate regression models. Weighted using normalized weights

distinctive. Compared to Whites, Blacks and other race individuals have significantly higher log odds of current food insufficiency while Asians have significantly lower log odds. Hispanics and Whites do not significantly differ in their log odds of current food insufficiency. Comparable to the findings for all households with work loss, Blacks and Hispanics households with children have higher log odds of future food insufficiency compared to Whites, while the other groups are not significantly different from Whites. Age, educational attainment, income, and the remaining controls work in similar ways for households with children as for all households.
To aid in interpretation of the logistic regression results, we used the Stata margins command to produce adjusted predicted probabilities of current and future food insufficiency by race/ethnicity with the control variables held constant at their mean. The predicted probabilities are produced using the logit regression coefficients from the fully adjusted models. Figure 1 displays the results for all households with work loss. Blacks, other race individuals, and Hispanics have the highest predicted probability of current and future food insufficiency (e.g., . 22 for current and .17 for future for Blacks). Figure 2 presents the results for households with recent work loss and children by racial/ethnicity. The predicted probability of 
Table 2 Weighted descriptive statistics among those with recent work loss, by race/ethnicity

\begin{tabular}{|c|c|c|c|c|c|c|c|c|c|c|}
\hline & \multicolumn{2}{|c|}{ Non-Hispanic White } & \multicolumn{2}{|c|}{ Non-Hispanic Black } & \multicolumn{2}{|c|}{ Non-Hispanic Asian } & \multicolumn{2}{|c|}{ Non-Hispanic Other } & \multicolumn{2}{|l|}{ Hispanic } \\
\hline & Mean & Std. Dev. & Mean & Std. Dev. & Mean & Std. Dev. & Mean & Std. Dev. & Mean & Std. Dev. \\
\hline Current food insufficiency & 14.70 & & 28.11 & $*$ & 10.07 & $*$ & 23.79 & $*$ & 23.63 & $*$ \\
\hline Future food insufficiency & 11.83 & & 21.41 & $*$ & 10.78 & $*$ & 17.34 & $*$ & 20.21 & $*$ \\
\hline \multicolumn{11}{|l|}{ Age categories } \\
\hline $18-29$ & 23.30 & & 19.96 & $*$ & 25.87 & $*$ & 23.31 & & 27.83 & $*$ \\
\hline $30-39$ & 21.87 & & 26.31 & $*$ & 24.38 & $*$ & 26.62 & $*$ & 25.61 & $*$ \\
\hline $40-49$ & 20.68 & & 23.98 & $*$ & 21.71 & & 21.97 & & 23.09 & $*$ \\
\hline $50-59$ & 23.40 & & 20.90 & $*$ & 20.88 & $*$ & 20.00 & $*$ & 17.82 & $*$ \\
\hline $60-64$ & 10.75 & & 8.84 & $*$ & 7.16 & $*$ & 8.10 & $*$ & 5.65 & $*$ \\
\hline Female & 50.51 & & 54.82 & $*$ & 49.40 & & 55.34 & $*$ & 48.90 & $*$ \\
\hline Less than high school & 4.95 & & 9.31 & $*$ & 10.18 & $*$ & 8.14 & $*$ & 21.91 & $*$ \\
\hline High school & 30.39 & & 35.19 & $*$ & 18.57 & $*$ & 28.64 & & 33.60 & $*$ \\
\hline Some college & 35.14 & & 35.74 & & 27.58 & $*$ & 40.03 & $*$ & 30.32 & $*$ \\
\hline College & 29.52 & & 19.77 & $*$ & 43.66 & $*$ & 23.19 & $*$ & 14.17 & $*$ \\
\hline Married & 54.76 & & 38.09 & $*$ & 56.13 & & 44.57 & $*$ & 48.55 & $*$ \\
\hline Never married & 29.88 & & 43.56 & $*$ & 34.96 & $*$ & 37.08 & $*$ & 36.11 & $*$ \\
\hline Widowed/sepa rated/divorced & 15.36 & & 18.35 & $*$ & 8.91 & $*$ & 18.35 & $*$ & 15.34 & \\
\hline Household size & 3.52 & 1.66 & 3.91 & $1.89 *$ & 4.15 & $1.77 *$ & 3.95 & $1.98 *$ & 4.40 & $1.95 *$ \\
\hline Household kids & 0.76 & 1.11 & 1.08 & $1.29 *$ & 0.81 & $1.09 *$ & 0.99 & $1.31 *$ & 1.18 & $1.31 *$ \\
\hline Household adults & 2.76 & 1.28 & 2.83 & $1.45 *$ & 3.35 & $1.47 *$ & 2.96 & $1.48 *$ & 3.22 & $1.49 *$ \\
\hline Own home & 66.80 & & 42.19 & $*$ & 66.46 & & 51.97 & $*$ & 48.59 & $*$ \\
\hline Rent home & 31.48 & & 54.89 & $*$ & 32.27 & & 44.79 & * & 49.36 & * \\
\hline Owe no house payment & 1.73 & & 2.93 & $*$ & 1.27 & $*$ & 3.23 & $*$ & 2.05 & $*$ \\
\hline Total household income category & 4.18 & 2.05 & 2.97 & $1.856 *$ & 4.24 & 2.13 & 3.55 & $2.03 *$ & 3.15 & $1.84 *$ \\
\hline Self-rated poor health & 2.58 & 1.06 & 2.77 & $1.07 *$ & 2.49 & $1.03 *$ & 2.78 & $1.09 *$ & 2.79 & $1.07 *$ \\
\hline \multirow[t]{2}{*}{ Month state unemployment rate } & 9.28 & 3.76 & 9.55 & 3.55 & 11.01 & $3.87 *$ & 9.77 & 4.02 & 10.51 & $3.66 *$ \\
\hline & N 314,485 & & $\mathrm{~N} 40,613$ & & N 20,993 & & N 21,296 & & N 54,589 & \\
\hline
\end{tabular}

Source: US Census Bureau Household Pulse Survey, Weeks 1-21, April 2020-December 2020

*indicates significantly different from Whites, $p<$ O.OS from weighted bivariate regression models. Weighted using normalized weights

current food insufficiency for all racial/ethnic groups is quite high relative to historical levels. For households with recent work loss and children, while the probability that food insufficiency has occurred in the last 7 days is high the future outlook for food sufficiency is more positive but still remains a significant social problem.

\section{Supplementary Analyses}

Some prior research examining racial/ethnic disparities in food insufficiency during the Covid-19 pandemic included a retrospective question about food insufficiency as a covariate when predicting current and future food insufficiency [9]. In sensitivity analyses, we tested multivariate models using a dichotomous indicator of food insufficiency prior to March 13, 2020. We estimated models with prior food insufficiency as a dependent variable as and a predictor of current and future food (results available from authors). As expected, there were significant racial/ethnic and SES disparities in prior week food insufficiency and prior week food insufficiency is a strong predictor of current and future food insufficiency. The patterns of current and future food insecurity remain even with the inclusion of prior food insecurity. Given the potential for misreporting of prior week food insufficiency [36] and that our substantive results for current and future food insufficiency persist, we do not include prior food insufficiency as a covariate in our main multivariate models. Instead, we focused on including established correlates of food insufficiency in our analyses.

In supplementary analysis among food insufficient households, we examined racial patterns in the reasons why respondents report not having enough to eat similar to Morales, Morales, and Beltrán [9]. The Household Pulse provides five response options and respondents can select all that apply. The options include not being able to afford enough food, not 
Table 3 Weighted descriptive statistics among those with recent work loss with children in the household, by race/ethnicity

\begin{tabular}{|c|c|c|c|c|c|c|c|c|c|c|}
\hline & \multicolumn{2}{|c|}{ Non-Hispanic White } & \multicolumn{2}{|c|}{ Non-Hispanic Black } & \multicolumn{2}{|c|}{ Non-Hispanic Asian } & \multicolumn{2}{|c|}{ Non-Hispanic Other } & \multicolumn{2}{|c|}{ Hispanic } \\
\hline & Mean & Std. Dev. & Mean & Std. Dev. & Mean & Std. Dev. & Mean & Std. Dev. & Mean & Std. Dev. \\
\hline Current food insufficiency & 16.60 & & 30.34 & $*$ & 12.04 & $*$ & 26.61 & $*$ & 25.67 & $*$ \\
\hline Future food insufficiency & 12.26 & & 21.68 & $*$ & 13.07 & & 16.49 & $*$ & 21.39 & $*$ \\
\hline \multicolumn{11}{|l|}{ Age categories } \\
\hline $18-29$ & 16.75 & & 18.20 & $*$ & 17.36 & & 17.73 & & 24.46 & $*$ \\
\hline $30-39$ & 31.05 & & 33.44 & $*$ & 27.14 & $*$ & 32.99 & $*$ & 31.31 & \\
\hline $40-49$ & 31.15 & & 28.46 & $*$ & 34.09 & $*$ & 28.72 & & 28.27 & $*$ \\
\hline $50-59$ & 16.87 & & 15.14 & $*$ & 18.45 & & 16.05 & & 13.12 & $*$ \\
\hline $60-64$ & 4.19 & & 4.76 & $*$ & 2.96 & $*$ & 4.52 & & 2.83 & $*$ \\
\hline Female & 53.72 & & 57.97 & $*$ & 50.09 & & 59.90 & $*$ & 52.31 & $*$ \\
\hline Less than high school & 6.11 & & 11.20 & $*$ & 12.37 & $*$ & 10.43 & $*$ & 26.19 & $*$ \\
\hline High school & 31.24 & & 37.43 & $*$ & 21.00 & $*$ & 29.94 & & 35.91 & $*$ \\
\hline Some college & 34.83 & & 34.79 & & 26.65 & $*$ & 39.27 & $*$ & 27.04 & $*$ \\
\hline College & 27.81 & & 16.58 & $*$ & 39.98 & $*$ & 20.36 & $*$ & 10.86 & $*$ \\
\hline Married & 66.50 & & 41.58 & $*$ & 70.29 & $*$ & 53.10 & $*$ & 55.09 & * \\
\hline Never married & 18.59 & & 41.36 & $*$ & 21.74 & $*$ & 28.34 & $*$ & 30.49 & * \\
\hline Widowed/separated/divorced & 14.92 & & 17.05 & * & 7.97 & * & 18.56 & $*$ & 14.42 & \\
\hline Household size & 4.54 & 1.50 & 4.75 & $1.71 *$ & 5.04 & $1.69^{*}$ & 5.00 & $1.86^{*}$ & 5.21 & $1.77 *$ \\
\hline Household kids & 1.86 & 1.00 & 1.98 & $1.13 *$ & 1.78 & $0.94 *$ & 2.05 & $1.17^{*}$ & 2.04 & $1.10 *$ \\
\hline Household adults & 2.69 & 1.15 & 2.77 & 1.33 & 3.26 & $1.44^{*}$ & 2.95 & $1.40^{*}$ & 3.17 & $1.39 *$ \\
\hline Own home & 70.65 & & 39.30 & $*$ & 68.70 & & 52.98 & $*$ & 47.71 & $*$ \\
\hline Rent home & 27.73 & & 57.84 & $*$ & 30.18 & & 44.08 & $*$ & 50.50 & * \\
\hline Owe no house payment & 1.63 & & 2.86 & $*$ & 1.11 & & 2.94 & $*$ & 1.78 & \\
\hline Total household income category & 4.30 & 2.05 & 2.83 & $1.82 *$ & 4.28 & 2.16 & 3.49 & $2.01 *$ & 3.06 & $1.80 *$ \\
\hline Self-rated poor health & 2.55 & 1.04 & 2.74 & $1.08 *$ & 2.50 & $1.04 *$ & 2.78 & $1.07 *$ & 2.79 & $1.05^{*}$ \\
\hline \multirow[t]{2}{*}{ Month state unemployment rate } & 9.26 & 3.77 & 9.54 & 3.52 & 11.03 & $3.92 *$ & 9.71 & 4.06 & 10.58 & $3.71^{*}$ \\
\hline & $\mathrm{N} 134,114$ & & N 22,026 & & N 9797 & & N 10,372 & & N 30,20 & \\
\hline
\end{tabular}

Source: US Census Bureau Household Pulse Survey, Weeks 1-21, April 2020-December 2020

*indicates significantly different from Whites, $p<$ O.OS from weighted bivariate regression models. Weighted using normalized weights

being able to buy food due to transportation, mobility, or health limitations, fear or not wanting to go out to buy food, not being able to get groceries or meals delivered, and stores not having the foods wanted. Each response was dichotomously coded ( $1=$ affirmative response, $0=$ otherwise $)$.

In all households, almost $55 \%$ cite affordability as a reason for not having enough to eat followed by $38 \%$ reporting stores lacking food, $28 \%$ reporting fear, $12 \%$ citing transportation issues, and $7 \%$ reporting delivery issues. The patterns are similar in households with children. For all racial/ethnic groups, affordability and stores not having the foods wanted are the main reasons cite for not having enough to eat. For Whites and Blacks, affordability is dominant, for Asians fear is cited almost as frequently as affordability, other race individuals frequently report transportation issues and stores not having the types of foods, and Hispanics notably report affordability and fear.
In separate weighted logistic regression models, we predicted each stated reason for food insufficiency for all households and for households with children (Appendix Tables 6 and 7). Among all food insufficient households with work loss, Blacks and other race individuals are significantly more likely while Asians are significantly less likely to report affordability than Whites as a reason for food insufficiency. Blacks, Asians, and other race individuals are significantly more likely than Whites to cite transportation issues as reasons for their food insufficiency. Patterns suggest significant differences in fear such that Asians, other race individuals, and Hispanic are significantly more likely than Whites to cite it as a reason for food insufficiency while Blacks are less likely. Blacks and Asians are less likely to cite delivery and store supply concerns as are Hispanics for store supply. The patterns are similar among food insecure households with work 
Table 4 Weighted logistic regression predicting food insufficiency among those with recent work loss

\begin{tabular}{|c|c|c|c|c|}
\hline & \multicolumn{2}{|c|}{ Current food insufficiency } & \multicolumn{2}{|c|}{ Future food insufficiency } \\
\hline & $\mathrm{b}$ & SE & $\mathrm{b}$ & SE \\
\hline \multicolumn{5}{|c|}{ Race/ethnicity (Ref=Non-Hispanic White) } \\
\hline Non-Hispanic Black & $0.333 * * *$ & 0.041 & $0.277 * * *$ & 0.039 \\
\hline Non-Hispanic Asian & $-0.330 * * *$ & 0.064 & 0.002 & 0.065 \\
\hline Non-Hispanic Other & $0.283 * * *$ & 0.053 & $0.160 * * *$ & 0.044 \\
\hline Hispanic & $0.062 *$ & 0.031 & $0.196 * * *$ & 0.053 \\
\hline \multicolumn{5}{|l|}{ Age categories $(\operatorname{Ref}=18-29)$} \\
\hline $30-39$ & $0.119 * * *$ & 0.027 & $0.366 * * *$ & 0.034 \\
\hline $40-49$ & $0.155 * * *$ & 0.027 & $0.484 * * *$ & 0.038 \\
\hline $50-59$ & $-0.165 * * *$ & 0.034 & $0.339 * * *$ & 0.038 \\
\hline $60-64$ & $-0.618 * * *$ & 0.044 & $0.088 *$ & 0.040 \\
\hline Female & $-0.131 * * *$ & 0.027 & $-0.143 * * *$ & 0.032 \\
\hline \multicolumn{5}{|c|}{ Education attainment (Ref=less than high school) } \\
\hline High school & $-0.141 * * *$ & 0.033 & $-0.236 * * *$ & 0.044 \\
\hline Some college & $-0.333 * * *$ & 0.037 & $-0.362 * * *$ & 0.043 \\
\hline College & $-0.776 * * *$ & 0.042 & $-0.669 * * *$ & 0.057 \\
\hline \multicolumn{5}{|l|}{ Marital status (Ref $=$ married $)$} \\
\hline Never married & $0.112 * * *$ & 0.030 & $-0.067 * *$ & 0.022 \\
\hline Widowed/separated/divorced & $0.373_{\text {**** }}$ & 0.035 & $0.169 * * *$ & 0.026 \\
\hline Household kids & $0.105 * * *$ & 0.009 & $0.038 * * *$ & 0.011 \\
\hline Household adults & $0.053 * * *$ & 0.013 & $0.017+$ & 0.009 \\
\hline \multicolumn{5}{|c|}{ Homeownership status $(\operatorname{Ref}=$ own home $)$} \\
\hline Rent home & $0.418 * * *$ & 0.019 & $0.362 * * *$ & 0.039 \\
\hline Owe no house payment & $0.782 * * *$ & 0.079 & $0.732 * * *$ & 0.087 \\
\hline Total household income category & $-0.286 * * *$ & 0.007 & $-0.250 * * *$ & 0.005 \\
\hline Self-rated poor health & $0.455 * * *$ & 0.012 & $0.451 * * *$ & 0.014 \\
\hline Month state unemployment rate & $-0.026 * * *$ & 0.003 & -0.003 & 0.004 \\
\hline Constant & $-1.881 * * *$ & 0.083 & $-2.447 * * *$ & 0.095 \\
\hline
\end{tabular}

Source: US Census Bureau Household Pulse Survey, Weeks 1-21, April 2020-December 2020

Sample size 451,976

*** $p<0.001, * * p<0.01, * p<0.05,+p<0.10$

Standard errors are clustered at the state level. Weighted using normalized weights loss and children with a few notable exceptions. Blacks and other race individuals do not significantly differ from Whites in reporting affordability as the reason for food insufficiency and Blacks do not differ from Whites in terms of fear.

Black households with work loss were more likely than Whites to cite affordability. Asians and other race individuals reported transportation as a reason for their food insufficiency. Blacks were more likely to reference transportation as a factor in their food insufficiency compared to Whites. Asians and Hispanics were more likely to report fear as a reason their food insufficiency compared to Whites. All groups were less likely than Whites to report that choice at stores was a factor in their food insufficiency.

\section{Discussion}

The Covid-19 pandemic has illuminated and exacerbated social disparities in well-being in American households. As record numbers of US adults lost work during the pandemic, multiple and often compounding hardships have ensued. Blacks and Hispanics and households with children have borne a disproportionate share of these hardships, particularly in terms of food insufficiency and work loss. We build on the work of other researchers to assess racial/ethnic disparities in current and future food insufficiency, and our research has several notable distinctions. A number of studies and policy briefs have demonstrated the alarming rise in work losses and food insecurity and their association $[1,19]$ or drawn 
Table 5 Weighted logistic regression predicting food insufficiency among those with recent work loss in household with children

Fig. 1 Predicted probability of food insufficiency by race/ethnicity, households with recent work loss. Error bars show 95\% confidence intervals. Each logit model includes all of the controls shown on Table 4. Predicted probabilities were generated using the Stata margins command with covariates at mean values

\begin{tabular}{|c|c|c|c|c|}
\hline & \multicolumn{2}{|c|}{ Current food insufficiency } & \multicolumn{2}{|c|}{ Future food insufficiency } \\
\hline & $\mathrm{b}$ & SE & $\mathrm{b}$ & SE \\
\hline \multicolumn{5}{|c|}{ Race/ethnicity (Ref=Non-Hispanic White) } \\
\hline Non-Hispanic Black & $0.262 * * *$ & 0.048 & $0.252 * * *$ & 0.045 \\
\hline Non-Hispanic Asian & $-0.326 * * *$ & 0.084 & 0.121 & 0.094 \\
\hline Non-Hispanic Other & $0.254 * * *$ & 0.060 & 0.019 & 0.060 \\
\hline Hispanic & 0.019 & 0.045 & $0.202 * * *$ & 0.061 \\
\hline \multicolumn{5}{|l|}{ Age categories $(\operatorname{Ref}=18-29)$} \\
\hline $30-39$ & $0.068 *$ & 0.032 & $0.276 * * *$ & 0.044 \\
\hline $40-49$ & $0.068+$ & 0.037 & $0.327 * * *$ & 0.066 \\
\hline $50-59$ & $-0.145 * * *$ & 0.044 & $0.285 * * *$ & 0.073 \\
\hline $60-64$ & $-0.508 * * *$ & 0.109 & -0.047 & 0.096 \\
\hline Female & -0.097 & 0.068 & $-0.117 * *$ & 0.043 \\
\hline \multicolumn{5}{|c|}{ Education attainment (Ref=less than high school) } \\
\hline High school & $-0.069+$ & 0.039 & $-0.219 * *$ & 0.073 \\
\hline Some college & $-0.267 * * *$ & 0.043 & $-0.363 * * *$ & 0.062 \\
\hline College & $-0.670 * * *$ & 0.055 & $-0.640 * * *$ & 0.078 \\
\hline \multicolumn{5}{|l|}{ Marital status $(\mathrm{Ref}=$ married $)$} \\
\hline Never married & $0.125 * * *$ & 0.035 & $-0.152 * * *$ & 0.044 \\
\hline Widowed/separated/divorced & $0.320 * * *$ & 0.046 & $0.176 * * *$ & 0.040 \\
\hline Household kids & $0.107 * * *$ & 0.014 & $0.081 * * *$ & 0.013 \\
\hline Household adults & $0.083 * * *$ & 0.017 & $0.024 *$ & 0.012 \\
\hline \multicolumn{5}{|c|}{ Homeownership status $(\operatorname{Ref}=$ own home $)$} \\
\hline Rent home & $0.400 * * *$ & 0.034 & $0.331 * * *$ & 0.050 \\
\hline Owe no house payment & $0.835 * * *$ & 0.103 & $0.706 * * *$ & 0.103 \\
\hline Total household income category & $-0.263 * * *$ & 0.011 & $-0.232 * * *$ & 0.008 \\
\hline Self-rated poor health & $0.401 * * *$ & 0.016 & $0.408 * * *$ & 0.016 \\
\hline Month state unemployment rate & $-0.027 * * *$ & 0.004 & 0.001 & 0.005 \\
\hline Constant & $-1.865 * * *$ & 0.110 & $-2.433 * * *$ & 0.150 \\
\hline
\end{tabular}

Source: US Census Bureau Household Pulse Survey, Weeks 1-21, April 2020-December 2020

Sample size 206,515

*** $p<0.001, * * p<0.01, * p<0.05,+p<0.10$

Standard errors are clustered at the state level. Weighted using normalized weights

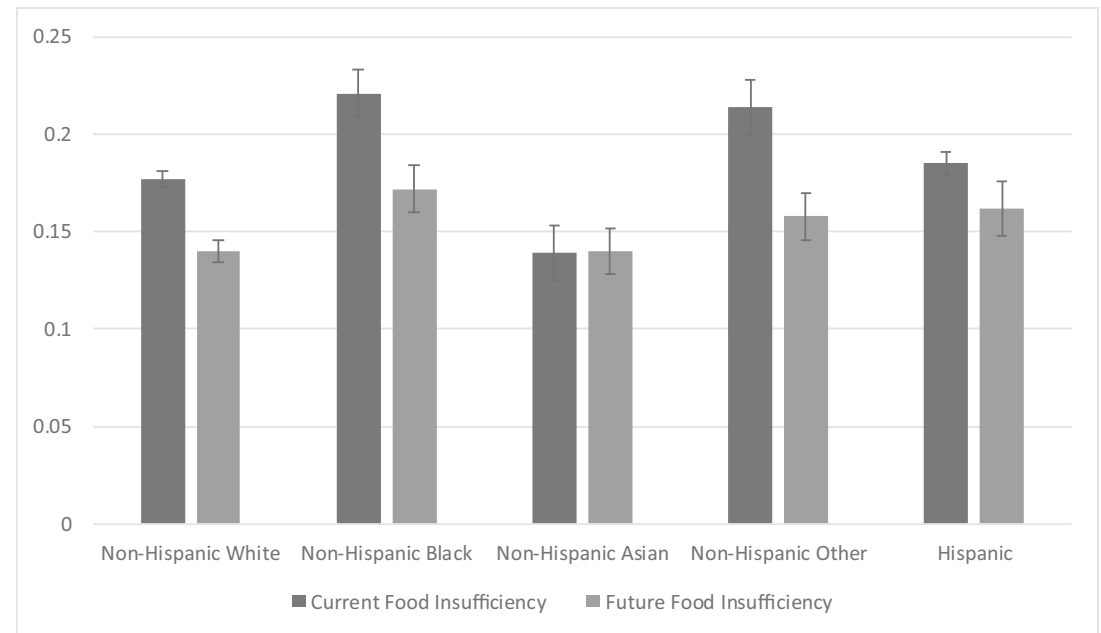


Fig. 2 Predicted probability of food insufficiency by race/ethnicity, households with recent work loss and children. Error bars show $95 \%$ confidence intervals. Each logit model includes all of the controls shown on Table 5. Predicted probabilities were generated using the Stata Margins command with covariates at mean values

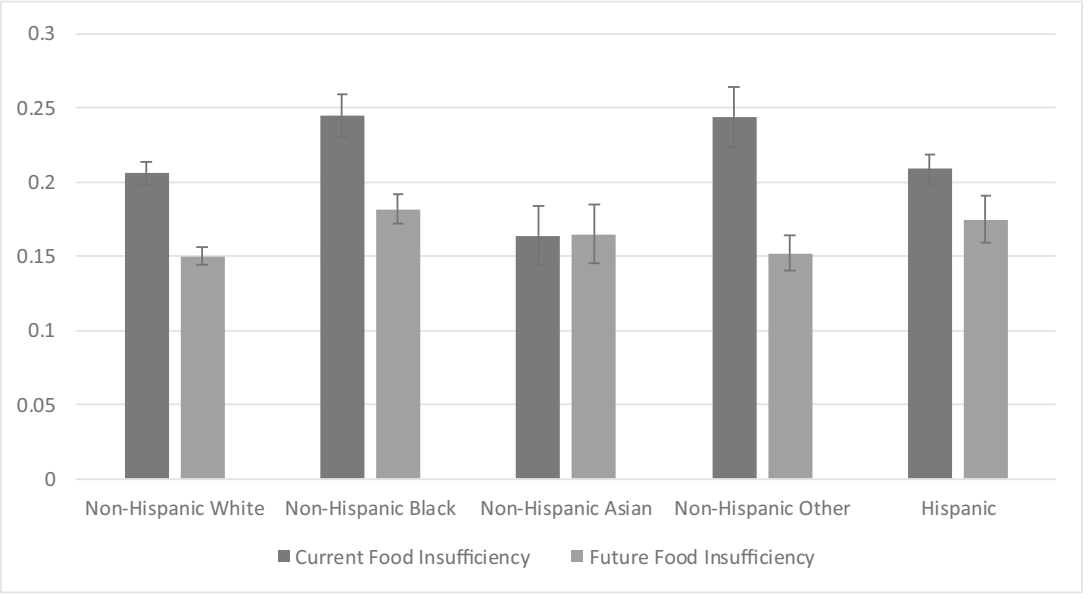

comparison of food insecurity by race/ethnicity [5, 9] or particularly for households with children. Other studies have focused on the impact of work losses on food insecurity. Though these studies provide insight into the immense and diffuse impact of the pandemic on household well-being, no study to date uses data spanning the Covid-19 pandemic in 2020 to examine food insecurity by race/ethnicity in households with work loss generally, and among households with recent work loss and children, thus underscoring the compounding nature of pandemic-induced hardships. Using the Household Pulse Survey data from the US Census Bureau, we assess the racial disparities in current and future food insufficiency among households with a recent work loss and households with children who have experienced a work loss. Importantly, we examine both current and future food insufficiency because they may capture related but distinct processes. Current food insufficiency likely captures the direct impact of race/ethnic differences in work loss and immediate needs while future food insufficiency may pick up trust in government and the compounding impacts of structural racism and distrust in institutions.

Our timely research continues to document the racial/ ethnic disparities in current and future food insufficiency during the Covid-19 pandemic from early to late 2020. The descriptive results reveal high levels of current and future food insufficiency in all households with recent work loss and acutely in households with children, specifically for Blacks, other race individuals, and Hispanics. The race/ethnic gaps persist in the multivariate models for current and future food insufficiency. Other socioeconomic indicators such as age, education attainment, marital status, and income operate in the expected direction on food insufficiency. Our results spanning much of the pandemic in 2020 corroborate evidence from early in the pandemic of racial/ethnic disparities in the reasons stated for food insufficiency [9]. Affordability, fear, and transportation issues were commonly cited. These reasons for food insufficiency and transportation and access issues in particularly highlight structural concerns related to racism and food deserts.

While our research describes the current high level of food insufficiency in American households, it is not without limitations. We focus on food insufficiency rather than food insecurity because the Household Pulse did not include the standard CPS food security supplemental 18 questions, but instead asked two questions about having enough and the types of food desired presently and in the future. Further, we are unable to distinguish households by the age of the children, which may have differing food needs and concerns. The Household Pulse only provides a dichotomous indicator of children under 18 rather than a complete household roster. Also, while we included multiple weeks (21) of the Pulse survey, cluster the errors at the state level, and control for the respondent's state and month-specific unemployment rate, other contextual factors may be omitted from the models. Finally, the survey did not ask for respondents' citizenship or immigration status which limits our ability to further disaggregate race/ethnic subgroups.

\section{Policy Implications}

To date several economic and social policies have been implemented to support households with work loss and in particular those with children. A key action was the Coronavirus Aid, Relief, and Economic Security (CARES) Act, passed at the end of March 2020, which increased weekly unemployment benefits by $\$ 600$. Another action was the passage of the Families First Covid Response Act which allowed states to allocate the maximum state SNAP benefits to enrolled households and removed work requirements, implemented the Pandemic Electronic Benefits Transfer (P-EBT) program to provide food benefits to households with children who received free/reduced cost meals at schools that were closed, and increased funding for emergency food programs such as food pantries and food banks [1]. Furthermore, many of these 
programs are have been extended into summer or fall 2021. Despite the implementation of social and economic policies, racial/ethnic disparities in current and future food insufficiency persisted throughout the first nine months of the pandemic. As the pandemic continues into 2021 and many working-age adults remain under or unemployed and children remain out of the school building, food insufficiency continues to be a critical concern, particularly for racial and ethnic minority populations.

\section{Conclusion}

The timely analysis presented provides insight into the food hardship households across American are facing during the
Covid-19 pandemic. The Covid-19 pandemic remains a sustained stressor in people's lives, with the potential for lasting adverse consequences that continue once the pandemic has ended. Food insufficiency, work losses, and other social and economic disadvantages have fallen disproportionately on non-white groups during the pandemic. These will likely compound to create serious health, financial, and educational disadvantages which require examination as data is made available. The pandemic has laid bare vulnerability to food insufficiency among American households and made clear that food insufficiency persists as a public health concern requiring timely and targeted policy actions that address food insufficiency and its drivers.

\section{Appendix}

Table 6 Weighted logistic regression predicting reasons for food insufficiency among food insecure households with recent work loss $(N=216,532)$

\begin{tabular}{|c|c|c|c|c|c|c|c|c|c|c|}
\hline & \multicolumn{2}{|l|}{ Afford } & \multicolumn{2}{|c|}{ Transportation } & \multicolumn{2}{|l|}{ Fear } & \multicolumn{2}{|l|}{ Delivery } & \multicolumn{2}{|l|}{ Stores } \\
\hline & $\mathrm{b}$ & SE & $\mathrm{b}$ & SE & $\mathrm{b}$ & SE & $\mathrm{b}$ & SE & $\mathrm{b}$ & SE \\
\hline \multicolumn{11}{|c|}{ Race/ Ethnicity (Ref=Non-Hispanic White) } \\
\hline Non-Hispanic Black & $0.146 * * *$ & 0.042 & $0.129^{*}$ & 0.057 & $-0.089 * *$ & 0.031 & $-0.137 *$ & 0.068 & $-0.428 * * *$ & 0.043 \\
\hline Non-Hispanic Asian & $-0.242 * * *$ & 0.042 & $0.475 * * *$ & 0.056 & $0.979 * * *$ & 0.046 & $-0.173 * *$ & 0.061 & $-0.769 * * *$ & 0.038 \\
\hline Non-Hispanic Other & $0.116^{*}$ & 0.048 & $0.338 * * *$ & 0.059 & $0.180 * * *$ & 0.036 & $0.452 * * *$ & 0.093 & -0.060 & 0.056 \\
\hline Hispanic & $-0.078+$ & 0.040 & 0.081 & 0.059 & $0.414 * * *$ & 0.030 & -0.040 & 0.060 & $-0.458 * * *$ & 0.041 \\
\hline
\end{tabular}

Source: US Census Bureau Household Pulse Survey, Weeks 1-21, April 2020-December 2020

All models include the covariates from Tables 4 and 5. Tables abbreviated for space

*** $p<0.001, * * p<0.01, * p<0.05,+p<0.10$

Standard errors are clustered at the state level

Weighted using normalized weights

Table 7 Weighted logistic regression predicting reasons for food insufficiency among food insecure households with recent work loss with children $(N$ $=106,326$ )

\begin{tabular}{|c|c|c|c|c|c|c|c|c|c|c|}
\hline & \multicolumn{2}{|l|}{ Afford } & \multicolumn{2}{|c|}{ Transportation } & \multicolumn{2}{|l|}{ Fear } & \multicolumn{2}{|l|}{ Delivery } & \multicolumn{2}{|l|}{ Stores } \\
\hline & $\mathrm{b}$ & SE & $\mathrm{b}$ & SE & $\mathrm{b}$ & SE & $\mathrm{b}$ & SE & $\mathrm{b}$ & SE \\
\hline \multicolumn{11}{|c|}{ Race/ Ethnicity (Ref=Non-Hispanic White) } \\
\hline Non-Hispanic Black & 0.105 & 0.069 & $0.160 * *$ & 0.059 & 0.006 & 0.049 & -0.139 & 0.100 & $-0.406 * * *$ & 0.067 \\
\hline Non-Hispanic Asian & $-0.250 * * *$ & 0.055 & $0.476^{* * *}$ & 0.061 & $1.007 * * *$ & 0.068 & -0.125 & 0.110 & $-0.862 * * *$ & 0.065 \\
\hline Non-Hispanic Other & 0.078 & 0.056 & $0.290 * *$ & 0.103 & $0.183 * *$ & 0.068 & $0.349 * * *$ & 0.096 & -0.048 & 0.05 \\
\hline Hispanic & $-0.166 * * *$ & 0.048 & 0.058 & 0.060 & $0.499 * * *$ & 0.048 & -0.045 & 0.120 & $-0.486 * * *$ & 0.058 \\
\hline
\end{tabular}

Source: US Census Bureau Household Pulse Survey, Weeks 1-21, April 2020-December 2020

All models include the covariates from Tables 4 and 5. Tables abbreviated for space

$* * * p<0.001, * * p<0.01, * p<0.05,+p<0.10$

Standard errors are clustered at the state level

Weighted using normalized weights 
Author Contribution All authors contributed to the study conception and design. Material preparation, data collection and analysis were performed by [Claire E. Altman], data preparation was performed by [Dashiell Nusbaum]. The first draft of the manuscript was written by [Claire E. Altman] and all authors commented on previous versions of the manuscript. All authors read and approved the final manuscript.

Data Availability Data are publicly available from the US Census Bureau.

Code Availability Stata was used for the analysis.

\section{Declarations}

Ethics Approval This is an observational study. The IRB has confirmed that no ethical approval is required.

Consent to Participate Not applicable.

Consent for Publication Not applicable.

Conflict of Interest The authors declare no competing interests.

Human and Animal Rights and Informed Consent Not applicable.

\section{References}

1. Rachidi A, Food insufficiency during the pandemic. 2020, American Enterprise Institute.

2. Economic Research Service. Food Security in the U.S.: Key Statistics. Food \& Nutrition Assistance 2020.

3. Waxman E, Gupta P, Karpman M. More than one in six adults were food insecure two months into the COVID-19 recession. Washington: Urban Institute; 2020.

4. Raifman J, Bor J, and Venkataramani A, Unemployment insurance and food insecurity among people who lost employment in the wake of COVID-19. MedRxiv, 2020.

5. Ziliak JP. Food hardship during the Covid-19 pandemic and great recession. Appl Econ Perspect Policy. 2021;43(1):132-52.

6. NPR, Robert Wood Johnson Foundation, and Harvard T.H.Chan School of Public Health, The impact of Coronavirus on households in major U.S. cities. 2020: https://media.npr.org/assets/img/2020/ 09/08/cities-report-090920-final.pdf.

7. Bauer L, The COVID-19 crisis has already left too many children hungry in America. 2020, The Hamilton Project.

8. Schanzenbach D and Pitts A, Estimates of food insecurity during the COVID-19 crisis: results from the COVID Impact Survey, week 1 (April 20-26, 2020), in Institute for Policy Research (IPR) Rapid Research Report, N.I.f.P. Research, Editor. 2020.

9. Morales DX, Morales SA, and Beltran TF, Racial/ethnic disparities in household food insecurity during the covid-19 pandemic: a nationally representative study. J Racial Ethn Health Disparities, 2020: p. 1-15.

10. Kochhar R, Hispanic women, immigrants, young adults, those with less education hit hardest by COVID-19 job losses, in Factank: News in the Numbers. 2020, Pew Research Center.

11. TED: The Economics Daily. 14.6 million private sector jobs lost during second quarter 2020. 2021; Available from: https://www. bls.gov/opub/ted/2021/14-6-million-private-sector-jobs-lostduring-second-quarter-2020.htm.
12. Fronstin P and Woodbury SA, How many Americans have lost jobs with employer health coverage during the pandemic? 2020, The Commonwealth Fund.

13. Terrell K, 8 occupations hit hardest by the pandemic in 2020 , in Work \& Jobs: Job Search. 2021, AARP: https://www.aarp.org/ work/job-search/info-2020/job-losses-during-covid.html.

14. U.S. Bureau of Labor Statistics. Supplemental data measuring the effects of the coronavirus (COVID-19) pandemic on the labor market. Labor Force Statistics from the Current Population Survey 2020.

15. Falk $\mathrm{G}$, et al., Unemployment rates during the COVID-19 pandemic: in brief. 2021, Congressional Research Service.

16. Center on Budget and Policy Priorities, Tracking the COVID-19 recession's effects on food, housing, and employment hardships, in Covid Hardship Watch. 2020.

17. Kim Y. To be hungry in the middle of the pandemic. In: in The New York Times. New York: The New York Times Company; 2020.

18. U.S. Bureau of Labor Statistics, Economic News Release, s.a. Summary Table A. Household data, Editor. 2021: Washington.

19. Despard M, et al. COVID-19 job and income loss leading to more hunger and financial hardship. Washington: Brookings Institution; 2020.

20. Parker K, Minkin R, Bennett J. Economic fallout from COVID-19 continues to hit lower-income americans the hardest. Washington: Pew Research Center: Social \& Demographic Trends; 2020.

21. Bitler M, Hoynes HW, and Schanzenbach DW, The social safety net in the wake of Covid-19, N.W.P. Series, Editor. 2020, National Bureau of Economic Research Cambridge, MA

22. Sáenz R and Sparks C, The inequities of job loss and recovery amid the COVID-19 pandemic, in Carsey Research National Issue Brief, U.o.N.H.C.S.o.P. Policy, Editor. 2020.

23. Bokun A, et al., The unequal impact of COVID-19 on children's economic vulnerability, ECONOFACT, Editor. 2020, The Fletcher School, Tufts University.

24. Coleman-Jensen A, et al. Household food security in the United States in 2019. Washington: US Department of Agriculture, Economic Research Service; 2020.

25. Gupta P, Gonzalez D, Waxman E. Forty percent of Black and Hispanic parents of school-age children are food insecure. Washington: Urban Institute; 2020.

26. Restrepo BJ, Rabbitt MP, and Gregory CA, The effect of unemployment on food spending and adequacy: evidence from Coronavirus-induced firm closures. Appl Econ Perspect Policy 2021.

27. Ahn S, Norwood FB. Measuring food insecurity during the COVID-19 pandemic of spring 2020. Appl Econ Perspect Policy. 2021;43(1):162-8.

28. Feng A, Schwabish J, and Spievack N, Racial and ethnic disparities in food insufficiency persist during the pandemic, in urban wire food and nutrition, U. Institute, Editor. 2020: https://www.urban. org/urban-wire/racial-and-ethnic-disparities-food-insufficiencypersist-during-pandemic.

29. Odoms-Young AM. Examining the impact of structural racism on food insecurity: implications for addressing racial/ethnic disparities. Family Community Health. 2018;41(Food Insecurity and Obesity):S3.

30. Hilmers A, Hilmers DC, Dave J. Neighborhood disparities in access to healthy foods and their effects on environmental justice. Am J Public Health. 2012;102(9):1644-54.

31. Spieler C, Racism has shaped public transit, and it's riddled with inequities, in UrbanEdge, K.I.f.U. Research, Editor. 2020, Rice University: https://kinder.rice.edu/urbanedge/2020/08/24/ transportation-racism-has-shaped-public-transit-americainequalities.

32. Pollack CE, Cubbin C, Sania A, Hayward M, Vallone D, Flaherty $\mathrm{B}$, et al. Do wealth disparities contribute to health disparities within 
racial/ethnic groups? J Epidemiol Community Health. 2013;67(5): 439-45.

33. Conley D. Being black, living in the red: race, wealth, and social policy in America. Berkeley: University of California Press; 2010.

34. United State Census Bureau. Household pulse survey: measuring social and economic impacts during the coronavirus pandemic. Household Pulse Survey 2021.

35. FRED Economic Data. Unemployment rate. 2021 [cited 2021; Available from: https://fred.stlouisfed.org/series/UNRATE.
36. Schanzenbach D and Pitts A, Food insecurity in the Census Household Pulse Survey Data Tables, in Institute for Policy Research (IPR) Rapid Research Report, N.I.f.P. Research, Editor. 2020.

Publisher's Note Springer Nature remains neutral with regard to jurisdictional claims in published maps and institutional affiliations. 